\title{
Uma proposta de seleção para caracteres quantitativos e qualitativos em aveia
}

\author{
A proposal for selecting quantitative and qualitative trais in oat
}

\author{
Giovani Benin ${ }^{1}$ Fernando Irajá Félix de Carvalho ${ }^{2}$ Antônio Costa Oliveira ${ }^{2}$ \\ José Antonio Gonzales da Silva ${ }^{3}$ Claudir Lorencetti ${ }^{3}$ Melissa Batista Maia ${ }^{3}$ \\ Volmir Sérgio Marchioro ${ }^{3}$ Fabio Freitas ${ }^{3}$ Irineu Hartwig ${ }^{4}$
}

\section{RESUMO}

\begin{abstract}
Em aveia (Avena sativa L.), a utilização de técnicas que minimizem os efeitos de ambiente na expressão do fenótipo e que facilitem a identificação de genótipos de superior rendimento de grãos, baixa estatura e tolerantes ao alumínio tóxico são aspectos de fundamental importância para o desenvolvimento de cultivares mais promissores e com adaptabilidade a áreas consideradas marginais. Desta forma, genótipos selecionados pelo método colméia de condução de populações segregantes, em três diferentes cruzamentos, foram submetidos a testes simultâneos para tolerância ao alumínio tóxico $\left(\mathrm{Al}^{+3}\right)$ e insensibilidade ao ácido giberélico $(A G 3)$, objetivando a identificação de constituições genéticas superiores. A técnica utilizada possibilitou a seleção de plantas de alto potencial produtivo, menor estatura (insensíveis ao $\left.\mathrm{AG}_{3}\right)$ e mais tolerantes ao $\mathrm{Al}^{+3}$, podendo ser aplicada com sucesso em programas de melhoramento genético com a cultura da aveia hexaplóide cultivada.
\end{abstract}

Palavras-chave: Avena sativa L., alumínio tóxico, ácido giberélico, melhoramento genético.

\section{ABSTRACT}

In oat (Avena sativa L.) techniques that minimize environmental effects on the expression of phenotype and facilitate the identification of high yielding genotypes are useful. Short stature and tolerance to toxic aluminum are important for the development of cultivars with adaptability to marginal areas. Thus, genotypes selected by the honeycomb method, in three different crosses, were subjected to simultaneous tests for aluminum tolerance $\left(\mathrm{Al}^{+3}\right)$ and insensibility to gibberelic acid $(A G 3)$, aiming the identification of superior genotypes. This technique enabled the selection of high yielding, short stature and $\mathrm{Al}^{+3}$ tolerant genotypes and could be applied in plant breeding programs involving cultivated hexaploid oat.
Key words: Avena sativa L., toxic aluminum, gibberelic acid, genetic improvement.

\section{INTRODUÇÃO}

A seleção para caracteres quantitativos é altamente influenciada pela manifestação do ambiente na expressão do fenótipo. Entretanto, o método colméia de condução de populações segregantes proposto por FASOULAS (1973), que preconiza a seleção do genótipo com base no fenótipo, através de comparações métricas em pequenas áreas, possibilita melhorar estimativas de herdabilidade e identificar com mais exatidão diferenças genéticas e efeitos de ambiente. Desta forma, é possível selecionar genótipos de grande potencial de rendimento ainda em gerações altamente segregantes.

A identificação de genótipos mais tolerantes ao alumínio tóxico e insensíveis ao ácido giberélico por meio do emprego de solução nutritiva tem sido utilizada com sucesso em trigo, permitindo imediata observação dos efeitos de injúrias de alumínio, pela inibição do crescimento da raiz, evitando os inconvenientes do uso do solo onde a intensidade de seleção não pode ser quantitativamente controlada. Além disso, DORNELLES et al. (1997), utilizando a técnica de hidroponia em solução nutritiva para

\footnotetext{
${ }^{1}$ Engenheiro Agrônomo Estudante do Curso de Doutorado em Agronomia (Fitomelhoramento) da Universidade Federal de Pelotas (UFPel), Pelotas, RS. Bolsista do CNPq. E-mail: giovbn@ pop.com.br - gibn@ibest.com.br

${ }^{2}$ Engenheiro Agrônomo (PhD.), Professor do Departamento de Fitotecnia da Faculdade de Agronomia Eliseu Maciel (FAEM), UFPel, Campus Universitário, CP 354, 96001-970, Pelotas, RS. E-mail: caravalho@ufpel.tche.br

${ }^{3}$ Estudante do Curso de Pós-graduação em Agronomia (Fitomelhoramento), UFPel.

${ }^{4}$ Estudante do Curso de Agronomia, UFPel.
} 
tolerância ao alumínio tóxico simultaneamente com a avaliação da sensibilidade ao ácido giberélico, demonstrou ser uma estratégia viável na seleção de plantas de baixa estatura e tolerantes ao alumínio.

A associação entre o caráter insensibilidade ao ácido giberélico e o caráter estatura de planta foi observado em trigo por FEDERIZZI et al. (1988) e DORNELLES et al. (1997), e em aveia por MILACH et al. (2002). A aplicação exógena de ácido giberélico na dose de 100ppm tem sido reportada como a de melhor resultado em trigo (FEDERIZZI et al., 1988; DORNELLES et al., 1997), possibilitando melhor resposta por parte dos genótipos altos e nenhuma resposta por parte dos baixos. O ponto determinante para alcançar níveis tóxicos do alumínio em trigo tem sido reportada em 10ppm (CAMARGO \& OLIVEIRA 1981), e 20ppm em aveia (SANCHES-CHACÓN et al., 2001).

Relatos sobre a tolerância ao alumínio em aveia indicam herança monogênica, com ação gênica de dominância (SANCHES-CHACÓN, 1998), e/ou controlado por um a dois genes dominantes (WAGNER, 1999). Diversos estudos demonstram que poucos genes de grande efeito no fenótipo controlam o caráter estatura de planta em aveia (MARSHAL \& MURPHY, 1981; FEDERIZZI \& QUALSET, 1989). Desta forma, é possível aplicar forte pressão de seleção para baixa estatura e tolerância ao $\mathrm{Al}^{+3}$ em fases iniciais dos programas de melhoramento.

Raros são os mecanismos de condução de populações segregantes que favorecem a seleção de caracteres quantitativos em gerações altamente segregantes. Por conseqüência, a grande maioria dos pesquisadores recomendam exercer forte pressão de seleção em caracteres qualitativos nas gerações com intensa segregação e, posteriormente, em presença de maior freqüência de homozigotos, intensificar a seleção para caracteres quantitativos. Desta maneira, os trabalhos têm que ser conduzidos de forma a não determinar uma redução drástica na população alvo, objetivando contornar as perdas de constituições genéticas importantes na combinação de genes responsáveis para desenvolver genótipos superiores. Conseqüentemente, a modificação nestes sistemas de condução de populações segregantes e o incremento na qualidade de seleção são os objetivos deste trabalho, ou seja, exercer forte pressão de seleção artificial para rendimento de grão nas gerações com grande frequiência de heterozigotos e com posterior seleção para caracteres qualitativos (alumínio tóxico e estatura de planta) em ambiente controlado.

\section{MATERIALEMÉTODOS}

Os experimentos foram conduzidos a campo e em laboratório nos anos de 2001 e 2002 na Faculdade de Agronomia Eliseu Maciel da Universidade Federal de Pelotas (FAEM/UFPel), município de Capão do Leão. O campo experimental possui um solo classificado como Podzólico Vermelho-amarelo da área de mapeamento de Pelotas (MORENO, 1961).

Quatrocentas plantas individuais $\mathrm{F}_{3}$ foram avaliadas pelo método colméia de condução de populações segregantes, independentemente para cada um dos três cruzamentos estudados: OR 2 x UPF 18, UPF 7 x CTC 5, OR 2 x UPF 7. Os genótipos foram semeados separadamente em linhas desencontradas de três metros de comprimento com espaçamento de $0,3 \mathrm{~m}$ entre e dentro de linhas. A seleção se restringiu às plantas de superior e inferior rendimento em relação à colméia, que correspondeu aos seis vizinhos mais próximos localizados no vértice de um hexágono; portanto, cada planta, circundada por outras seis, todas a mesma distância, só foi selecionada quando sua produção de grãos foi superior ou inferior as demais plantas do hexágono.

As plantas selecionadas foram avaliadas de forma simultânea para tolerância ao alumínio tóxico e sensibilidade ao ácido giberélico, utilizando a técnica descrita por CAMARGO \& OLIVEIRA (1981) e adaptada por DORNELLES et al. (1997). Dez sementes por repetição, num total de três repetições, foram previamente desinfestadas, colocadas em placas de Petry individualizadas forradas com papel germinador umedecido com água destilada e levadas para germinar em câmera BOD a uma temperatura de $20^{\circ} \mathrm{C}$ com iluminação permanente, onde permaneceram por um período de três dias até iniciarem o processo de germinação.

As sementes pré-germinadas com $2 \mathrm{~mm}$ de raiz foram transferidas para uma tela de plástico adaptada a tampa de um recipiente com capacidade de 5,5 litros, contendo solução nutritiva completa, de modo a ficarem em contato permanente com a solução. Os recipientes foram colocados em tanque banho-maria com água a uma temperatura de $25 \pm 1^{\circ} \mathrm{C}$ com iluminação permanente, com o auxílio de resistências adaptadas ao tanque e ligados a um sistema de arejamento para dotação de oxigênio necessário ao desenvolvimento normal do sistema radicular, por um período de 48 horas. Depois de completado este período, as telas com as plântulas foram transferidas para recipientes com solução tratamento contendo 20ppm de $\mathrm{Al}^{3+}$, onde permaneceram por mais 48 horas. Posteriormente, as telas retornaram à solução nutritiva completa por 72 
horas. Após este período, as telas com as plântulas foram transferidas para novos recipientes com solução nutritiva mais 100ppm de $\mathrm{AG}_{3}$ com $\mathrm{pH} 7$ por 168 horas. Após, foram aferidos os caracteres indicativos de tolerância ao alumínio e sensibilidade ao ácido giberélico.

A avaliação dos caracteres para tolerância ao alumínio tóxico foi feita pela aferição do recrescimento da raiz (REC) com o auxílio de uma régua graduada, a partir do ponto de dano causado pela toxicidade do $\mathrm{Al}^{3+}$ na raiz principal. Os caracteres indicativos de sensibilidade ao ácido giberélico foram aferidos com o auxílio de uma régua graduada com a qual foram medidos em cm: a inserção da folha (IPF), tomada da base do colmo até a altura do encontro da emersão da $1^{\underline{a}}$ folha; comprimento da $1^{\mathrm{a}}$ folha (CPF), comprimento da $2^{\underline{a}}$ folha (CSF) e estatura de plântula (EPL), quantificada da base da plântula ao seu ápice.

Para a aferição do caráter estatura de planta (EST) e rendimento de grãos (REN) foi instalado um experimento a campo na safra agrícola de 2002, em delineamento experimental de blocos casualizados com três repetições, utilizando sementes dos mesmos genótipos avaliados em hidroponia. As parcelas foram constituídas de três linhas com 1,5m de comprimento, com espaçamento de $0,20 \mathrm{~m}$ entre linhas. Foi empregada uma densidade de 250 sementes viáveis por $\mathrm{m}^{2}$. Entre parcelas e nas bordaduras foi semeado um genótipo de trigo de porte baixo. O caráter EST foi determinado pela média de quatro notas em diferentes pontos da parcela, 21 dias após a antese, computada pelo comprimento do colmo em centímetros da superfície do solo até o ápice da inflorescência, excluindo as aristas. Para a determinação do rendimento de grãos, as parcelas foram trilhadas individualmente. Com a média das repetições foi estipulado o rendimento de grãos em kg.ha-1 .

Os dados foram submetidos à análise de variância e comparados pelo teste de Scott e Knott (SCOTT \& KNOTT, 1974). A associação entre caracteres foi estimada pela correlação de Pearson (STEEL \& TORRIE, 1980). As análises foram realizadas com emprego do programa computacional Genes (CRUZ, 2001).

\section{RESULTADOSE DISCUSSÃO}

Os caracteres indicativos da tolerância a toxicidade do alumínio e a insensibilidade ao ácido giberélico revelaram diferenças significativas a $1 \%$ de probabilidade de erro para todos os caracteres avaliados, sendo um indicativo da resposta diferenciada dos genótipos testados. Os coeficientes de variação oscilaram de 6,3 a 17,4\% (Tabela 1), conferindo boa precisão às estimativas preditas. Entretanto, coeficientes de variação de maior magnitude indicam necessidade de obter maior precisão na avaliação para comprimento da segunda folha. Na Tabela 1, também estão incluídas as médias dos caracteres analisados, comparadas pelo teste de Scott e Knott. Os cultivares padrões UPF 18 (suscetível) e UPF 19 (tolerante) foram utilizados como referências de suscetibilidade e tolerância ao alumínio tóxico, respectivamente (SANCHES-CHACÓN et al., 2001). Os cultivares UPF 18 e UPF 19 apresentaram recrescimentos de 25,3 e $33 \mathrm{~mm}$, respectivamente. A análise dos genótipos selecionados para superior e inferior rendimento de grãos, nos três cruzamentos avaliados, possibilitou a identificação de diferentes graus de suscetibilidade e tolerância ao alumínio tóxico, sendo um indicativo da presença de variabilidade nas populações estudas e da viabilidade de utilização do cultivo hidropônico na seleção de genótipos mais tolerantes. Plantas consideradas não tolerantes tiveram menores elongamentos, evidenciando a paralisação do crescimento da raiz, devido a uma inibição da elongação das células (FOY et al., 1978), e apresentaram a região meristemática engrossada e de coloração mais escura, que segundo FOY et al. (1978), são ineficientes na absorção de nutrientes e água.

Ainda na tabela 1 , a formação dos grupos de superior e inferior rendimento de grãos possibilita inferência sobre o método de seleção utilizado. $\mathrm{O}$ $\mathrm{Cr}_{2} \mathrm{G}_{\text {sup }}$ e $\mathrm{Cr}_{3} \mathrm{G}_{\text {sup }}$ foram os que apresentaram maior tolerância ao $\mathrm{Al}^{+3}$, com um recrescimento radicular de $27 \mathrm{~mm}$ e $26 \mathrm{~mm}$, respectivamente. Os menores índices de recrescimento foram observados para o $\mathrm{Cr}_{1} \mathrm{GO}_{\text {Inf }} \mathrm{e}$ $\mathrm{Cr}_{2} \mathrm{G}_{\text {Inf }}$, com recrescimento radicular de $14,8 \mathrm{~mm}$ e $18,6 \mathrm{~mm}$, respectivamente. Estes resultados indicam que o método colméia de condução de populações segregantes, através da estratificação do ambiente e seleção de plantas para alto potencial de rendimento de grãos, possibilitou também identificar genótipos mais tolerantes ao alumínio tóxico.

A correlação entre as variáveis REC, RN, IPF, CPF, CSF, EPL e EST apontou associação entre todas as variáveis mensuradas, com exceção das combinações RC x CPF e REC x CSF (Tabela 2). A associação significativa entre $\operatorname{REN} x \operatorname{REC}(0,3925)$ fornece subsídio a seleção indireta para tolerância ao $\mathrm{Al}^{+3}$, através da seleção de plantas de maior rendimento de grãos. As maiores magnitudes de associação observadas entre REC x EPL $(0,4806)$ e REC $x \operatorname{EST}(0,4103)$ indicam a possibilidade de seleção de genótipos mais tolerantes ao $\mathrm{Al}^{+3}$ através da seleção 
Tabela 1 - Médias dos caracteres recrescimento em alumínio (REC), inserção da $1^{\mathrm{a}}$ folha (IPF), comprimento da $1^{\mathrm{a}}$ folha (CPF), comprimento da $2^{a}$ folha (CSF), estatura de plântula (EPL), rendimento de grãos (RN) e estatura de planta (EST) de genótipos selecionados pelo método colméia para superior e inferior rendimento de grãos de plantas individuais nos cruzamentos UPF 18 X CTC $5\left(\mathrm{Cr}_{1}\right)$, OR 2 X UPF $7\left(\mathrm{Cr}_{2}\right)$ e OR 2 X UPF $18\left(\mathrm{Cr}_{3}\right)$ e média dos grupos superior e inferior, incluindo os padrões CTC 5, OR 2, UPF 7, UPF 18 e UPF 19. Pelotas, Universidade Federal de Pelotas, RS, 2003.

\begin{tabular}{|c|c|c|c|c|c|c|c|c|c|c|c|c|c|c|}
\hline \multirow{2}{*}{$\begin{array}{l}\text { Genótipos } \\
\mathrm{Cr}_{1} \mathrm{Sup}_{1}\end{array}$} & \multicolumn{2}{|c|}{$\operatorname{REC}^{1}(\mathrm{~mm})$} & \multicolumn{2}{|c|}{$\mathrm{RN}^{2}\left(\mathrm{~kg} \cdot \mathrm{ha}^{-1}\right)$} & \multicolumn{2}{|c|}{$\operatorname{IPF}^{1}(\mathrm{~cm})$} & \multicolumn{2}{|c|}{$\mathrm{CPF}^{1}(\mathrm{~cm})$} & \multicolumn{2}{|c|}{$\operatorname{CSF}^{1}(\mathrm{~cm})$} & \multicolumn{2}{|c|}{$\mathrm{EPL}^{1}(\mathrm{~cm})$} & \multicolumn{2}{|c|}{$\operatorname{EST}^{2}(\mathrm{~cm})$} \\
\hline & 13,3 & $e^{*}$ & 3033 & $\mathrm{c}$ & 6,1 & $\mathrm{c}$ & 18,2 & $\mathrm{~b}$ & 15,6 & $\mathrm{a}$ & 25,2 & $\mathrm{~b}$ & 106 & $\mathrm{a}$ \\
\hline $\mathrm{Cr}_{1} \mathrm{Sup}_{2}$ & 30,4 & $\mathrm{~b}$ & 2333 & $\mathrm{~d}$ & 6,9 & $\mathrm{~b}$ & 18,0 & $\mathrm{~b}$ & 12,2 & $\mathrm{~b}$ & 25,2 & $\mathrm{~b}$ & 96 & $\mathrm{a}$ \\
\hline $\mathrm{Cr}_{1} \mathrm{Sup}_{3}$ & 22,8 & d & 2533 & d & 5,4 & $\mathrm{~d}$ & 16,2 & $\mathrm{c}$ & 15,1 & $\mathrm{a}$ & 23,5 & $\mathrm{~b}$ & 90 & b \\
\hline $\mathrm{Cr}_{1} \mathrm{Sup}_{4}$ & 17,6 & $\mathrm{e}$ & 3700 & $\mathrm{~b}$ & 6,9 & $\mathrm{~b}$ & 17,8 & $\mathrm{~b}$ & 15,3 & $\mathrm{a}$ & 25,3 & $\mathrm{~b}$ & 90 & $\mathrm{~b}$ \\
\hline $\mathrm{Cr}_{1} \mathrm{Sup}_{5}$ & 16,3 & $\mathrm{e}$ & 3000 & $\mathrm{c}$ & 6,7 & $\mathrm{~b}$ & 16,8 & $\mathrm{~b}$ & 15,7 & $\mathrm{a}$ & 25,8 & $\mathrm{a}$ & 111 & $\mathrm{a}$ \\
\hline $\mathrm{Cr}_{2} \mathrm{Sup}_{1}$ & 22,0 & $\mathrm{~d}$ & 3800 & $\mathrm{~b}$ & 7,8 & $\mathrm{a}$ & 18,1 & $\mathrm{~b}$ & 17,2 & $\mathrm{a}$ & 25,9 & $\mathrm{a}$ & 95 & a \\
\hline $\mathrm{Cr}_{2} \mathrm{Sup}_{2}$ & 25,3 & $\mathrm{c}$ & 3366 & $\mathrm{c}$ & 8,3 & $\mathrm{a}$ & 17,6 & $\mathrm{~b}$ & 11,3 & $\mathrm{~b}$ & 26,1 & $\mathrm{a}$ & 100 & $\mathrm{a}$ \\
\hline $\mathrm{Cr}_{2} \mathrm{Sup}_{3}$ & 21,3 & d & 4300 & $\mathrm{a}$ & 7,0 & $\mathrm{~b}$ & 17,9 & $\mathrm{~b}$ & 14,9 & $\mathrm{a}$ & 24,3 & $\mathrm{~b}$ & 104 & $\mathrm{a}$ \\
\hline $\mathrm{Cr}_{2} \mathrm{Sup}_{4}$ & 25,6 & $\mathrm{c}$ & 4500 & $\mathrm{a}$ & 6,5 & $\mathrm{~b}$ & 18,1 & $\mathrm{~b}$ & 12,0 & $\mathrm{~b}$ & 24,7 & $\mathrm{~b}$ & 95 & a \\
\hline $\mathrm{Cr}_{2} \mathrm{Sup}_{5}$ & 40,7 & $\mathrm{a}$ & 4066 & $\mathrm{~b}$ & 6,7 & $\mathrm{~b}$ & 18,4 & $\mathrm{a}$ & 17,7 & $\mathrm{a}$ & 27,2 & $\mathrm{a}$ & 100 & $\mathrm{a}$ \\
\hline $\mathrm{Cr}_{3} \mathrm{Sup}_{1}$ & 20,3 & $\mathrm{~d}$ & 4300 & $\mathrm{a}$ & 6,7 & $\mathrm{~b}$ & 17,7 & $\mathrm{~b}$ & 15,2 & $\mathrm{a}$ & 25,5 & $\mathrm{~b}$ & 85 & $\mathrm{~b}$ \\
\hline $\mathrm{Cr}_{3} \mathrm{Sup}_{2}$ & 40,8 & $\mathrm{a}$ & 3000 & $\mathrm{c}$ & 7,6 & $\mathrm{a}$ & 19,2 & $\mathrm{a}$ & 15,2 & $\mathrm{a}$ & 27,5 & $\mathrm{a}$ & 101 & a \\
\hline $\mathrm{Cr}_{3} \mathrm{Sup}_{3}$ & 25,9 & $\mathrm{c}$ & 4400 & $\mathrm{a}$ & 7,0 & $\mathrm{~b}$ & 18,8 & $\mathrm{a}$ & 13,3 & $\mathrm{a}$ & 25,4 & $\mathrm{~b}$ & 106 & $\mathrm{a}$ \\
\hline $\mathrm{Cr}_{3} \mathrm{Sup}_{4}$ & 30,0 & $\mathrm{~b}$ & 4566 & $\mathrm{a}$ & 7,8 & $\mathrm{a}$ & 20,9 & $\mathrm{a}$ & 15,5 & $\mathrm{a}$ & 29,0 & $\mathrm{a}$ & 110 & $\mathrm{a}$ \\
\hline $\mathrm{Cr}_{3} \mathrm{Sup}_{5}$ & 14,9 & $\mathrm{e}$ & 3400 & $\mathrm{c}$ & 6,4 & $\mathrm{~b}$ & 19,4 & $\mathrm{a}$ & 17,2 & $\mathrm{a}$ & 26,1 & $\mathrm{a}$ & 100 & $\mathrm{a}$ \\
\hline $\mathrm{Cr}_{1} \operatorname{Inf}_{1}$ & 15,2 & $\mathrm{e}$ & 900 & $\mathrm{f}$ & 6,8 & $\mathrm{~b}$ & 17,7 & $\mathrm{~b}$ & 11,9 & $\mathrm{~b}$ & 24,9 & $\mathrm{~b}$ & 85 & $\mathrm{~b}$ \\
\hline $\mathrm{Cr}_{1} \operatorname{Inf}_{2}$ & 16,6 & $\mathrm{e}$ & 900 & $\mathrm{f}$ & 5,8 & $\mathrm{c}$ & 15,3 & $\mathrm{c}$ & 10,0 & $\mathrm{c}$ & 21,2 & $\mathrm{c}$ & 90 & $\mathrm{~b}$ \\
\hline $\mathrm{Cr}_{1} \operatorname{Inf}_{3}$ & 15,3 & $\mathrm{e}$ & 900 & $\mathrm{f}$ & 5,9 & $\mathrm{c}$ & 16,8 & $\mathrm{~b}$ & 14,0 & $\mathrm{a}$ & 23,3 & $\mathrm{~b}$ & 84 & $\mathrm{~b}$ \\
\hline $\mathrm{Cr}_{1} \mathrm{Inf}_{4}$ & 11,9 & $\mathrm{e}$ & 1066 & $\mathrm{f}$ & 6,9 & $\mathrm{~b}$ & 17,1 & $\mathrm{~b}$ & 5,0 & $\mathrm{c}$ & 24,0 & $\mathrm{~b}$ & 96 & $\mathrm{~b}$ \\
\hline $\mathrm{Cr}_{1} \mathrm{Inf}_{5}$ & 15,1 & $\mathrm{e}$ & 1000 & $\mathrm{f}$ & 6,5 & $\mathrm{~b}$ & 17,3 & $\mathrm{~b}$ & 13,3 & $\mathrm{a}$ & 23,6 & $\mathrm{~b}$ & 80 & $\mathrm{~b}$ \\
\hline $\mathrm{Cr}_{2} \operatorname{Inf}_{1}$ & 32,0 & $\mathrm{~b}$ & 1133 & $\mathrm{e}$ & 6,8 & $\mathrm{~b}$ & 17,3 & $\mathrm{~b}$ & 12,6 & $\mathrm{~b}$ & 24,7 & $\mathrm{~b}$ & 98 & $\mathrm{a}$ \\
\hline $\mathrm{Cr}_{2} \operatorname{Inf}_{2}$ & 13,3 & $\mathrm{e}$ & 700 & $\mathrm{f}$ & 6,0 & $\mathrm{c}$ & 17,5 & $\mathrm{~b}$ & 8,9 & $\mathrm{c}$ & 18,3 & $\mathrm{~d}$ & 90 & $\mathrm{~b}$ \\
\hline $\mathrm{Cr}_{2} \operatorname{Inf}_{3}$ & 21,7 & $\mathrm{~d}$ & 1000 & $\mathrm{f}$ & 4,9 & $\mathrm{~d}$ & 14,8 & $\mathrm{c}$ & 15,5 & $\mathrm{a}$ & 23,1 & $\mathrm{~b}$ & 78 & $\mathrm{~b}$ \\
\hline $\mathrm{Cr}_{2} \mathrm{Inf}_{4}$ & 14,3 & $\mathrm{e}$ & 1300 & $\mathrm{e}$ & 5,4 & $\mathrm{~d}$ & 14,2 & $\mathrm{c}$ & 9,6 & c & 18,8 & $\mathrm{~d}$ & 90 & $\mathrm{~b}$ \\
\hline $\mathrm{Cr}_{2} \operatorname{Inf}_{5}$ & 11,5 & $\mathrm{e}$ & 600 & $\mathrm{f}$ & 5,9 & $\mathrm{c}$ & 14,6 & $\mathrm{c}$ & 8,66 & $\mathrm{c}$ & 20,2 & $\mathrm{c}$ & 78 & $\mathrm{~b}$ \\
\hline $\mathrm{Cr}_{3} \operatorname{Inf}_{1}$ & 13,5 & $\mathrm{e}$ & 1200 & $\mathrm{e}$ & 6,4 & $\mathrm{~b}$ & 17,1 & $\mathrm{~b}$ & 15,4 & $\mathrm{a}$ & 24,9 & $\mathrm{~b}$ & 100 & a \\
\hline $\mathrm{Cr}_{3} \operatorname{Inf}_{2}$ & 15,3 & $\mathrm{e}$ & 900 & $\mathrm{f}$ & 5,6 & $\mathrm{~d}$ & 17,5 & $\mathrm{~b}$ & 17,3 & $\mathrm{a}$ & 24,4 & $\mathrm{~b}$ & 94 & $\mathrm{a}$ \\
\hline $\mathrm{Cr}_{3} \operatorname{Inf}_{3}$ & 25,2 & $\mathrm{c}$ & 1600 & e & 6,2 & $\mathrm{c}$ & 13,4 & $\mathrm{c}$ & 9,40 & $\mathrm{c}$ & 19,6 & $\mathrm{~d}$ & 96 & $\mathrm{a}$ \\
\hline $\mathrm{Cr}_{3} \operatorname{Inf}_{4}$ & 21,6 & d & 1433 & e & 7,6 & $\mathrm{a}$ & 18,6 & $\mathrm{a}$ & 10,0 & $\mathrm{c}$ & 26,1 & $\mathrm{a}$ & 96 & $\mathrm{a}$ \\
\hline $\mathrm{Cr}_{3} \operatorname{Inf}_{5}$ & 43,7 & $\mathrm{a}$ & 1300 & $\mathrm{e}$ & 7,3 & $\mathrm{a}$ & 15,5 & $\mathrm{a}$ & 11,0 & $\mathrm{~b}$ & 25,6 & $\mathrm{a}$ & 110 & $\mathrm{a}$ \\
\hline UPF 18 & 25,3 & $\mathrm{c}$ & 2916 & $\mathrm{c}$ & 7,3 & $\mathrm{a}$ & 20,4 & $\mathrm{a}$ & 14,8 & $\mathrm{a}$ & 27,9 & $\mathrm{a}$ & 102 & $\mathrm{a}$ \\
\hline UPF 7 & 26,7 & $\mathrm{c}$ & 2366 & $\mathrm{~d}$ & 5,9 & $\mathrm{c}$ & 16,8 & $\mathrm{~b}$ & 7,33 & $\mathrm{c}$ & 22,8 & $\mathrm{~b}$ & 85 & $\mathrm{~b}$ \\
\hline UPF 19 & 33,0 & $\mathrm{~b}$ & 3133 & $\mathrm{c}$ & 6,1 & $\mathrm{c}$ & 16,8 & $\mathrm{~b}$ & 19,0 & $\mathrm{a}$ & 24,9 & $\mathrm{~b}$ & 100 & a \\
\hline $\begin{array}{l}\text { Média de } \\
\text { Grupos }\end{array}$ & REC & & REN & & IPF & & $\mathrm{CPF}$ & & $\mathrm{CSF}$ & & EPL & & EST & \\
\hline $\mathrm{Cr}_{1} \mathrm{G}_{\text {Sup }}$ & 20,1 & $\mathrm{~b}$ & 2920 & $\mathrm{~b}$ & 6,4 & $\mathrm{~b}$ & 17,4 & $\mathrm{c}$ & 14,8 & $\mathrm{a}$ & 25,0 & $\mathrm{~b}$ & 98 & $\mathrm{a}$ \\
\hline $\mathrm{Cr}_{2} \mathrm{G}_{\text {Sup }}$ & 27,0 & $\mathrm{a}$ & 4006 & $\mathrm{a}$ & 7,2 & $\mathrm{a}$ & 18,1 & $\mathrm{~b}$ & 14,6 & $\mathrm{a}$ & 25,6 & $\mathrm{~b}$ & 98 & a \\
\hline $\mathrm{Cr}_{3} \mathrm{G}_{\text {Sup }}$ & 26,0 & $\mathrm{a}$ & 3933 & $\mathrm{a}$ & 7,1 & $\mathrm{a}$ & 19,2 & $\mathrm{a}$ & 15,3 & $\mathrm{a}$ & 26,7 & $\mathrm{a}$ & 100 & $\mathrm{a}$ \\
\hline $\mathrm{Cr}_{1} \mathrm{G}_{\mathrm{Inf}}$ & 14,8 & d & 953 & $\mathrm{~d}$ & 6,4 & $\mathrm{~b}$ & 16,8 & $\mathrm{c}$ & 10,8 & c & 23,4 & $\mathrm{c}$ & 87 & b \\
\hline $\mathrm{Cr}_{2} \mathrm{G}_{\mathrm{Inf}}$ & 18,6 & $\mathrm{c}$ & 946 & $\mathrm{~d}$ & 5,8 & $\mathrm{c}$ & 15,7 & $\mathrm{~d}$ & 11,0 & c & 21,0 & $\mathrm{~d}$ & 86 & b \\
\hline $\mathrm{Cr}_{3} \mathrm{G}_{\mathrm{Inf}}$ & 23,7 & $\mathrm{~b}$ & 1286 & $\mathrm{c}$ & 6,6 & $\mathrm{~b}$ & 17,0 & $\mathrm{c}$ & 13,0 & $\mathrm{~b}$ & 23,9 & $\mathrm{c}$ & 99 & $\mathrm{a}$ \\
\hline Média & 22,3 & & 2371 & & 6,5 & & 17,0 & & 13,4 & & 24,4 & & 95,4 & \\
\hline $\mathrm{CV}$ & 12,2 & & 11,81 & & 8,6 & & 7,2 & & 17,4 & & 6,32 & & 10,1 & \\
\hline
\end{tabular}

* médias seguidas da mesma letra em coluna, não diferem estatisticamente pelo teste de Scott Knott em 5\% de probabilidade de erro. ${ }^{1}$ caracteres avaliados em laboratório.

${ }^{2}$ caracteres avaliados a campo. 
Tabela 2 - Coeficientes de correlação fenotípica de Pearson entre os caracteres recrescimento (REC), rendimento de grãos (REN), inserção da folha (IPF), comprimento da $1^{\underline{a}}$ folha (CPF), comprimento da $2^{\underline{a}}$ folha (CSF), estatura de plântula (EPL) e estatura de planta (EST). Pelotas, Universidade Federal de Pelotas, RS. 2003.

\begin{tabular}{|c|c|c|c|c|c|c|}
\hline & REC & $\mathrm{RN}$ & IPF & CPF & CSF & EPL \\
\hline REC & - & & & & & \\
\hline RN & $0,3925^{*}$ & - & & & & \\
\hline IPF & $0,3784 *$ & $0,4510^{*}$ & - & & & \\
\hline $\mathrm{CPF}$ & $0,2082^{\mathrm{ns}}$ & $0,5829 *$ & $0,5927^{*}$ & - & & \\
\hline CSF & $0,2232^{\text {ns }}$ & $0,4963^{*}$ & $-0,0233^{\mathrm{ns}}$ & $0,3871^{*}$ & - & \\
\hline EPL & $0,4806^{*}$ & $0,6199 *$ & $0,6118 *$ & $0,8745^{*}$ & $0,5760 *$ & - \\
\hline EST & $0,4103^{*}$ & $0,4570^{*}$ & $0,3521 *$ & $0,4060^{*}$ & $0,3267 *$ & $0,6154 *$ \\
\hline
\end{tabular}

* Significativo a $5 \%$ de probabilidade de erro, pelo teste t, a n-2 G.L. $(0,325)$.

${ }^{n s}$ Não significativo.

de genótipos de maior estatura de plântula e de planta, respectivamente. Entretanto, essas estimativas são de pouca utilidade aos programas de melhoramento genético de aveia, pois, tendem a dificultar a seleção de genótipos que combinem insensibilidade ao $\mathrm{AG}_{3} \mathrm{e}$ tolerância ao alumínio, pela técnica de cultivo hidropônico. A estimativa de correlação de 0,6154 entre EST x EPL fornece subsídios à seleção de genótipos de aveia de menor estatura através da sensibilidade ao ácido giberélico. Entre os caracteres mensurados para sensibilidade ao $\mathrm{AG}_{3}$, o maior grau de associação foi observado entre a estatura de plântula e o comprimento da primeira folha $(0,8745)$, indicando que a EPL pode ser utilizada de forma mais fácil e eficiente em substituição a IPF e CSF, os quais necessitam de aferições minuciosas. Resposta similar foi obtida por CANCI et al. (1997), onde a estatura de planta foi aferida pela distância da inserção da raiz à extremidade a extremidade a folha mais desenvolvida. O uso do ácido giberélico na seleção de genótipos quanto à estatura já é bastante conhecido na literatura (GALI \& GREGORY, 1977; FEDERIZZI et al., 1988), porém sua utilização na seleção de genótipos de aveia ainda não tinha sido testada.

A existência de variabilidade genética é condição essencial para o melhorista poder exercer pressão de seleção artificial sobre qualquer população de plantas. A contribuição relativa de cada caráter para a dissimilaridade genética, observada na tabela 3, permite identificar que o caráter REC foi o que mais contribuiu para explicar a dissimilaridade genética entre os genótipos avaliados, contribuindo com $55,85 \%$ para a dissimilaridade total, demonstrando que o conjunto de genótipos avaliados possui ampla variabilidade genética para tolerância ao $\mathrm{AL}^{+3}$, concordando com BARBIERI et al. (2001) e confirmando a viabilidade de utilização da técnica de cultivo hidropônico em discriminar esta variabilidade. Entre os caracteres indicativos da sensibilidade ao $\mathrm{AG}_{3}$, os caracteres estatura de plântula e inserção da $1^{\text {a }}$ folha, com contribuições relativas de 14,10 e $13,14 \%$, respectivamente, foram eficientes em discriminar o conjunto de genótipos avaliados, indicando que devem ser priorizados na seleção genótipos insensíveis à aplicação exógena de $\mathrm{AG}_{3}$. O comprimento da $1^{\text {a }}$ folha e comprimento da segunda folha apresentaram estimativas de $\mathrm{S}_{\text {.v }}$ de menor magnitude, não revelando, por conseguinte, importância para a diferenciação dos genótipos avaliados.

As concentrações de $20 \mathrm{ppm}$ de $\mathrm{Al}^{+3}$ e de 100 pmm de $\mathrm{AG}_{3}$ foram eficientes na identificação precoce de genótipos de aveia com diferentes níveis de tolerância ao alumínio tóxico e sensibilidade ao ácido giberélico. A identificação de genótipos insensíveis ao ácido giberélico pode ser efetuada através dos caracteres estatura de plântula, inserção da primeira folha e comprimento da primeira folha. Entretanto, o caráter estatura de planta é o mais apropriado na seleção de constituições genéticas para porte de planta e insensibilidade ao ácido giberélico.

\section{CONCLUSÃO}

A utilização do método colméia de condução de populações segregantes para a seleção precoce de caracteres quantitativos e posterior avaliação simultânea para tolerância ao $\mathrm{Al}^{+3} \mathrm{e}$ insensibilidade ao $\mathrm{AG}_{3}$ demonstra ser uma técnica viável a ser empregada nos programas de melhoramento genético com a cultura da aveia hexaplóide cultivada. 
Tabela 3 - Contribuição relativa para a dissimilaridade genética $\left(\mathrm{S}_{\mathrm{v}^{*}}\right)$ dos caracteres relacionados à tolerância ao $\mathrm{Al}^{+3}$ e sensibilidade ao ácido giberélico, baseada na estatística S de SINGH (1981). Pelotas, Universidade Federal de Pelotas, RS, 2003.

\begin{tabular}{|c|c|c|c|}
\hline \multirow{2}{*}{ Caracteres avaliados } & \multicolumn{3}{|c|}{ Dissimilaridade genética } \\
\hline & $S_{\cdot v^{\prime}}$ & $\%$ & $\%$ acumulada \\
\hline Recrescimento em alumínio (REC) & 12116,22 & 55,85 & 55,85 \\
\hline Estatura da plântula (EPL) & 3071,86 & 14,10 & 69,95 \\
\hline Inserção da $1^{\underline{a}}$ folha (IPF) & 2863,03 & 13,14 & 83,09 \\
\hline Comprimento da $1^{\mathrm{a}}$ folha (CPF) & 1631,25 & 7,48 & 90,57 \\
\hline Comprimento da $2^{\mathrm{a}}$ folha (CSF) & 2048,00 & 9,40 & 100,00 \\
\hline
\end{tabular}

\section{REFERÊNCIASBIBLIOGRÁFICAS}

BARBIERI, R.L. et al. Variabilidade genética entre genótipos de aveia hexaplóide quanto a tolerância a toxidade do alumínio. In: REUNIÃO DA COMISSÃO BRASILEIRA DE PESQUISA DE AVEIA 21., 2001, Lages. Anais... Lages : Universidade do Estado de Santa Catarina, 2001. p.40-41.

CAMARGO, O.C.E. de; OLIVEIRA, O.F. Tolerância de cultivares de trigo a diferentes níveis de alumínio em solução nutritiva e no solo. Bragantia, Campinas, v.40, p.21-23, 1981.

CANCI, P.C. et al. Diferentes ambientes para a avaliação de sensibilidade ao ácido giberélico em genótipos de trigo (Triticum aestivum L.). Ciência Rural, Santa Maria, v.27, n.1, p.21-25, 1997.

CRUZ, C.D. Programa genes: aplicativo computacional em genética e estatística. Viçosa : UFV, 2001. 648p.

DORNELLES, A.L.C. et al. Avaliação simultânea para tolerância ao alumínio e sensibilidade ao ácido giberélico em trigo hexaplóide. Pesquisa Agropecuária Brasileira, Brasília, v.32, n.9, p.893-896, 1997.

FALCONER, D.S. Introdução à genética quantitativa. Viçosa : UFV, 1987. 279p.

FASOULAS, A. A new approach to breeding superior yielding varieties. Thessaloniki, Greece : Aristotelian University, 1973. 42p.

FEDERIZZI, L.C. et al. Avaliação da resposta de genótipos de trigo (Triticum aestivum L.) de diferentes estaturas à aplicação de ácido giberélico no estádio de plântula. Revista do Centro Ciências Rurais, Santa Maria, v.18, n.2, p.149$161,1988$.

FEDERIZZI, L.C.; QUALSET, C.O. Genetics of plant height reduction and panicle type in oat. Crop Science, Madison, v. 29, p.551-557, 1989
FOY, G.D.; CHANEY, R.L.; WHITE, M.C. The physiology of metal toxicity in plants. Annual Review Plant Physiology, Bethesda, v.29, p.511-566, 1978.

GALI, M.D.; GREGORY, R.S. A rapid method for early generation selection of dwarf genotypes in wheat. Euphytica, Wageningen, v.26, p.733-738, 1977.

MARSHALL, H.G.; MURPHY, C.F. Inheritance of dwarfism in three oat crosses and relationship of height to panicle and culm length. Crop Science, v.21, p.335-338, 1981.

MILACH, S.C.K. et al. Plant height and gibberellic acid response of oat dwarf lines. Crop Science, v.42, p.11471154, 2002.

MOREno, A.J. Clima do Rio Grande do Sul. Porto Alegre : Secretaria da Agricultura/RS, 1961. 41p.

SÁNCHEZ-CHACÒN, C.D. Herança da tolerância a sensibilidade e sensibilidade à tolerância do alumínio em aveia (Avena sativa L.). 1998. 73f. Tese (Doutorado em Agronomia-Fitotecnia) - Programa de Pós-graduação em Agronomia, Universidade Federal do Rio Grande do Sul.

SÁNCHEZ-CHACÓN, C.D. et al. Avaliação de cultivares elite de aveia hexaplóide quanto a toxidade do alumínio em cultivo hidropônico. In: REUNIÃO DA COMISSÃO BRASILEIRA DE PESQUISA DE AVEIA, 21., 2001, Lages. Anais... Lages: Universidade do Estado de Santa Catarina, 2001. p.90-91.

SCOTT, A. J.; KNOTT, M.A. Cluster analysis methods for grouping means in the analysis of variance. Biometrics, Washington, v.30, p.507-512, 1974.

STEEL, R.G.D.; TORRIE, J.H. Principles and procedures of statistics: a biometric approach. 2.ed. New York : McGraw-Hill, 1980. 633p.

WAGNER, C.W. Herança da tolerância à toxicidade do alumínio em aveia. 1999. 62f. Dissertação (Mestrado em Agronomia-Fitotecnia) - Programa de Pós-graduação em Agronomia, Universidade Federal do Rio Grande do Sul. 